"torture" will guarantee that these topical issues will be scrutinized by readers.

In a word, Window is a very personal account, on all fronts. The personalities of individual apes are as carefully presented as any cast of characters in a play. Conversations with colleagues, quoted verbatim, convey the excitement of collaborative research in the bush. Again and again, telling vignettes make the point more compellingly than any judiciously qualified generalization could do.

Most importantly, Jane Goodall's viewpoint (and so her personality) have virtually defined our impressions of chimpanzee nature, at least in the Englishspeaking world. This is an awesome responsibility for any scientist.

When Louis Leakey arranged for Jane Goodall to begin studies of the chimpanzees at Gombe, he predicted that it would take ten years to understand them. This seemed excessively cautious at the time. Now, after 30 years, one can only look forward to the next decade of continuing research, and to Goodall's next account of it.

W. C. McGrew is a Reader in the Department of Psychology, University of Stirling, Stirling FK9 4LA, UK

\section{It's a jungle}

\section{Tim Lincoln}

Brazzaville Beach. By William Boyd. Sinclair-Stevenson, London: 1990. £13.95. To be published in the United States early next summer by Morrow.

In this, his fifth novel, William Boyd has returned to home ground, to Africa, for one of the two intertwined stories that make up the narrative. But otherwise the book is a daring and imaginative departure from his previous works. The principal character is a woman, the young and self-assured Hope Clearwater, a botanist turned ethologist, into whose skin Boyd has convincingly written himself (convincingly, that is, as far as a male reader can tell). And the subject matter is mathematics and primatology, with at the bottom of it all the moral that in intellectual endeavours winning, or being seen to win, is everything.

The first story centres on the shadowy figure of John Clearwater, said to be a brilliant mathematician. After four years at Caltech working on game theory, he has returned to Britain, to Imperial College in London, to meet and marry Hope, and to match his brains against the challenge of discovering a simple formulation for turbulence. The second story (chronologically the later) is set in a vaguely defined, war-ravaged part of Africa, at the Grosso Arvore primate research centre. It is there that Hope has gone, after the mental battering unwittingly meted out by her husband, to work under Eugene Mallabar, who has devoted the best part of his life to the study of chimpanzees. Interspersed between the two are brief ruminations, which veer close to the extremes of pretentiousness and profundity, and which in large part come from the present, from Brazzaville Beach, where Hope has eventually washed up. From the

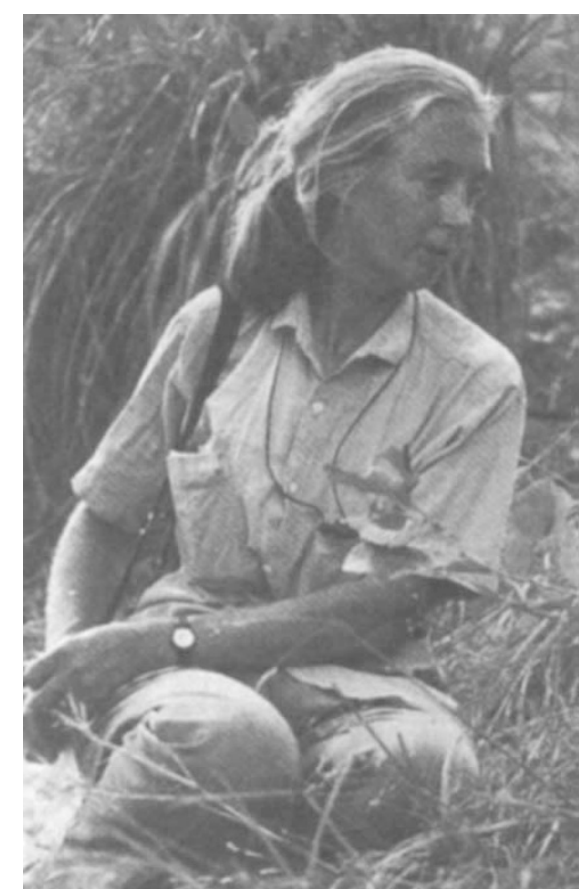

Jane Goodall - inspiration for Hope? (Reproduced from Through a Window*).

beach she examines her life and muses on why her marriage to John Clearwater, and the research at Grosso Arvore, went so badly awry.

Both episodes are narrated in spare and beautifully controlled style. John Clearwater slides into insanity, inch by inch, by way of the fevered digging of holes in search of inspiration, an affair with the wife of an acned physicist, and (towards the end) treatment by electroconvulsive therapy. His agony is to have been on the verge of, but to have been beaten to, what would have been a claim to mathematical immortality in the form of the Clearwater set — a simple algorithm "that would reproduce the magical, infinite variety of the natural world". Life amongst some of the bit players is none too happy either. There is for example Hope's gruesome sister, married to a solicitor and "sinking in the quicksand of prudence, moderation and propriety" in the stuffy respectability of the English home counties.

But it is in Africa, among the chimpanzees, that the starkest of horrors (and the best joke) lie. To followers of the career of Jane Goodall* the chain of events will be

* Jane Goodall's most recent book, Through a Window. My Thirty Years with the Chimpanzees of Gombe, is reviewed on page 371 of this issue. uncannily familiar. Boyd has founded his fiction curiously close to fact, in that for Grosso Arvore one could well read Gombe - not only in the background (research students not merely from the United States but explicitly from Stanford, the evening chore of writing up field notes, the controversial existence of an artificial feeding area, the round of lecture tours), but in the two main occurrences. Of these one is a kidnapping of researchers; the other is a north-south rift in the chimpanzee community, subsequent brutal attacks by the northerners upon the breakaway group, and the shattering observation that chimps are capable of infanticide and cannibalism.

At this point, Boyd parts company with Goodall. In discovering the 'chimpanzee wars', Hope threatens Mallabar's cherished theories, his sources of money and his celebrity status, built in part through his books The Peaceful Primate and Primate's Progress. But experienced operator that he is, the shocking revelations are deftly appropriated as his own. When the third book appears, Hope, like her former husband, has become a loser, literally a footnote to history.

Brazzaville Beach is probably best taken as no more and no less than a compelling novel. Yet, together with other straws in the wind, it is tempting to see in it a sign that one of the two cultures (a matter now widely and wrongly considered passé) is taking the other seriously. That hope is no doubt unfounded. There is, though, the other Hope - William Boyd should persuade himself to get his splendid literary creation off the beach and back into the scientific jungle where she belongs.

Tim Lincoln is News and Views Editor of Nature.

\section{Original lingo?}

\section{John C. Marshall}

Language and Species. by Derek Bickerton. Chicago University Press: 1990. Pp. 297. \$24.95.

BY the close of 1832, the Beagle had reached Tierra del Fuego and was anchored in Good Success Bay. Captain Fitzroy sent a party ashore, and the young Charles Darwin met his first Fuegians in their native habitat. In his diary for 18 December, Darwin wrote: "Their language does not deserve to be called articulate. Capt. Cook says it is like a man clearing his throat; to which may be added another very hoarse man trying to shout and a third encouraging a horse with that peculiar noise which is made in one side of the mouth." Some forty years later, Darwin had the insight (and the courage) 
to admit he was wrong (".... I took a very erroneous view of the nature and capabilities of the Fuegians").

Nonetheless, the diary entry does reveal why it is nowdays so acutely embarrassing to read most of the anthropological linguistics written in the nineteenth century. Language is what makes us human, but some are more human than others. Colonial exploitation (economic, cultural and religious) demanded that, in the great chain of being, "primitive savages' should fall roughly half way between chimpanzee and bourgeoisie. Exponents of the theory of 'mental evolution' duly interpreted their observations to show that the speech of 'lower races' was mere jabbering, eked out by pantomime, and that their mentation consequently allowed neither abstraction nor generalization.

In the twentieth century, two basic facts put the damper on speculation about language origins. First, all extant languages have equal expressive power (although achieved by superficially distinct means); and second, the fossil record of the hominid line will not support reliable argument about the cognitive capacities of the brains that once inhabited those skulls. For the most part, the domain became the province of the dilettante. It must accordingly have required considerable chutzpa for a professional linguist to launch wholeheartedly into Language and Species as an earnest topic of extended research.

Derek Bickerton is professor of linguistics at the University of Hawaii. Much of his own fieldwork has been on pidgins (which may in some sense be 'primitive' or protolanguages) and their conversion into creoles (which are definitely the real thing'). A creole language "is what results when a pidgin, created by adults, is learned by the children of those adults." The interest of the transition lies in the observation that whereas pidgins are pretty much a jumble of words, creoles exhibit "the same type of structure as any other natural human language". The propositional meaning of an utterance in a pidgin must be 'guessed' on the basis of lexical semantics and the context of situation; but the determination of 'thematic roles' (who did what to whom) in a creole sentence is controlled by the formal principles and parameters of universal grammar.

If, as Bickerton (coherently, albeit controversially) argues, the "jump from protolanguage to language (can be made) in a single generation", the biological implications are strong and profound: the process of creolization becomes a laboratory in which we can see (in relatively 'pure' form) the innate predispositions that the child brings to language acquisition as a species-specific characteristic. The behaviourist alternative to 'nativism' - that a general purpose learning device 'induces' grammatical structure from a rich input of exemplary instances becomes decidedly unappealing if the features acquired are simply not there in the pidgin environment. In Bickerton's view, creoles are thus "an unusually direct expression (of the) capacity to recreate language in the absence of any specific model from which the properties of language could be 'learned' in the ways we normally learn things."

Language and Species sets this discussion in the context of Noam Chomsky's government and binding theory (the only serious account of syntactic structures that currently exists). Bickerton's lucid description of the theory serves to draw a fairly clear line between protolanguage and the full system. That demarcation permits Bickerton (with justification) to have his cake and eat it with respect to the evolution of language. The gestural devices that can be taught to apes, the 'language' of small children (under the age of two), and the 'invented' pidgins that allow communication between adult speakers of mutually incomprehensible languages seem to fall together as limited, yet extremely useful systems of representation and expression. But there is a qualitative Rubicon between that level of linguistic labelling and the formal syntactic properties that then emerge in the language of the older child and that characterize all natural languages, creoles included.

Bickerton can thus avoid the counterintuitive view that the capacity for language in the species developed wholly out of the blue whilst recognizing the abruptness of the transition to true language. That the notion of 'gradualism' in both the phylogenetic and the ontogenetic development of language has been a conspicuous failure does not imply that there is no functional precursor to act as a springboard to syntax. Yet Bickerton's "language biogram hypothesis", derived from his creole data, is actually a more extreme 'nativist' position than that adopted by Chomsky. Chomsky's 'selectionist' theory of language acquisition presupposes that the child is presented with the linguistic evidence required to set a parameter of the syntax to the value represented in the adult language to which he or she is exposed; but Bickerton seems to be claiming that creoles possess features for which there is literally no evidence in the linguistic environment. Concerning the neurobiology of such leaps, however, Bickerton can add little to the handwaving that has always been such a lamentable feature of attempts to go beyond description in this area.

It would be unfair though to conclude on that kind of negative note. The evolution of language is a fascinating topic, and insofar as we know anything about it, Bickerton's Language and Species is the best introduction we have. On the other hand, Bickerton himself stresses the pessimistic, sociocultural reflection that language enables us to create a wide range of "dysfunctional representations" of human nature which may yet kill us all. It was not the apple that tempted Eve so much as the seductive sentiments of the serpent.

John C Marshall is at the Neuropsychology Unit, University Department of Clinical Neurology, The Radcliffe Infirmary, Oxford OX2 6HE, UK.

\section{Purplish prose}

\section{Henry Gee}

Lucy's Child: The Discovery of a Human Ancestor. By Donald Johanson and James Shreeve. Viking: 1990. Pp.318 16.99. Published in the United States by Avon, New York. $\$ 10.95$ (pbk).

SCHOOLCHILDREN will be familiar with the class of creative writing generally described as "what I did in my summer holidays". The idea behind this literary form is to convince the reader that one has spent the vacation engaged in various improving pursuits, rather than hanging out on street corners, following the exploits of the Teenage Mutant Ninja Turtles or listening to Bon Jovi records. Typical examples of the genre inflate every routine trip to the shops into an epic voyage of discovery.

Donald Johanson had hoped to spend his summer holidays exploring palaeontological virgin territory in Ethiopia in search of fossil hominids to add to "Lucy" and the so-called "first family" - the spectacular discoveries that formed the basis of his reputation. A sequel to his bestselling Lucy: The Beginnings of Humankind would surely have been on the cards. But thwarted by the tides of politics, he had to make do with the wellworked and tourist-encrusted rocks of Olduvai Gorge in Tanzania instead. A fine shopping expedition was beginning to take shape.

Nevertheless, Johanson and a small crew unearthed remains of a diminutive hominid in sediments dated at 1.8 million years old. The description was eventually published in Nature (327, 205-209; 1987), which is not bad for a holiday jaunt. The hominid was catalogued as OH62 (short for Olduvai hominid number 62) and was interpreted in the paper as Homo habilis despite its very small stature and postcranial features arguably reminiscent of Australopithecus. To attribute $\mathrm{OH} 62$ as Homo put further strains on the validity of $H$. habilis as a single taxon (see the News and Views article by Bernard Wood which accompanied Johanson's paper). Naturally enough, much is made in Lucy's Child 